\title{
The Distinction among Colonialism, Imperialism and Racism: Conrad's Subversion and Rewriting of Traditional British National Identity
}

\author{
LI Qiuyu ${ }^{1} \&$ CHEN Bing ${ }^{2}$
}

School of Foreign Studies, Nanjing University, China

To cite this article: LI Qiuyu \& CHEN Bing. (2021). The Distinction among Colonialism, Imperialism and Racism: Conrad's Subversion and Rewriting of Traditional British National Identity. Asia-Pacific Journal of Humanities and Social Sciences, 1(4), 086-093, DOI: 10.53789/j. 1653-0465.2021.0104.012

To link to this article: https: //doi. org/10.53789/j. 1653-0465.2021.0104. 012

\begin{abstract}
Traditional British adventure fiction often portrays British citizens as noble, civilized, upright and brave colonial gentlemen. Having known the nature of colonization and colonizers, Conrad subverts such discourse and tries to rewrite traditional British national identity. However, because he is a man who opposes colonialism, but supports imperialism and racism, the British national identity that Conrad portrays remains the elements related to imperialism and racism and reflects his own understanding to the implication of gentleman. The ideal British national identity in his mind is the imperial gentleman with pure British descent and humanitarian spirit and brave enough to take the responsibility.
\end{abstract}

Keywords: Conrad; British adventure fiction; national identity; subversion; rewriting

Notes on the contributors: LI Qiuyu is a doctoral student in English languages and literature at Nanjing University with academic interest in British and American literature; CHEN Bing is a professor in English languages and literature at Nanjing University with academic interest in British and American literature. 


\title{
殖民主義、帝國主義、種族主義之辨
}

一一康拉德對傳統英國民族身份的顛覆與改寫

\author{
李秋宇 ${ }^{1}$ 陳 兵 $^{2}$
}

南京大學外國語學院

\begin{abstract}
摘 要: 傳統英國歷險小說往往把英國公民塑造成高尚、文明、正直、勇敢的殖民紳士形象。康拉德在認清殖民活 動及殖民者的本質之後数此進行了顛覆, 並試圖改鴧傅統的英國民族身份。但由於其反對殖民主義, 卻支持帝國 主義和種族主義, 康拉德塑造的英國民族身份保留了契合帝國主義和種族主義語境的成分, 卻也反映出了他自己 對紳士内涵的獨特理解, 是擁有純正英國血統, 勇於承擔而又具有人道主義精神的帝國紳士形象。
\end{abstract}

關鍵詞: 康拉德; 英國歷險小說; 民族身份; 顛覆; 改寫

\section{引言}

19 世紀後半葉, 大英帝國進人軍事帝國主義階段, 殖民擴張的殘暴及剝削本質開始顯露。同時, 法、德、 俄、意等國崛起, 英國逐漸喪失海上霸主及世界工廠地位, 加上布爾戰爭的失利, “愛爾蘭自治法案” ( Ireland Home Rule) 的提出等等一系列事件動搖了英國民眾對大英帝國的信心及信念。適逢民族主義大潮席捲歐 洲,一場關於英國民族身份建構及反思的討論在英國境内開始展開,不少作家都參與其中。作為維多利亞時 代晚期具有代表性的作家之一, 康拉德 (Joseph Conrad，1857-1924) 自然也不例外。然而,學者們大都認同 康拉德對傳統的殖民地人民及英國公民形象進行了顛覆, 並試圖重構前者的形象, 卻很少有人涉及其對大英 帝國公民形象的建構問題。如認為不同於傳統歷險小說對殖民地人民的 “非人化” 描寫, 康拉德代表作《黑 暗之心》(Heart of Darkness) 中的黑人 “可愛得多”, 竞是小說中 “最快樂、最健康、最有生命力” 的存在, ${ }^{2}$ 而白 人則是 “嗜血成性” ${ }^{3}$ 的 “空心人” ${ }^{4}$ 。其實, 正如薩義德 (Edward W. Said) 所說: “自我身份的建構一一因為 在我看來, 身份, 不管東方的還是西方的, 法國的還是英國的, 不僅顯然是獨特的集體經驗之彙集, 最終都是 一種建構一一牽涉到與自己相反的“他者” 身份的建構, 而且總是牽涉到對與 ‘我們, 不同的特質的不斷闆釋 和再闡釋”。 ${ }^{5}$ 換言之, 自我與他者的身份都是基於建構產生的,而且二者的身份建構互為參照。因此, 在關 注殖民地人民身份建構問題的同時, 英國民族身份的建構問題同樣值得探討。那麼, 作為一名波蘭裔、英國 籍的歸化作家, ${ }^{\circ}$ 康拉德筆下的英國公民形象又有怎樣的特點呢?

\section{一、康拉德與殖民主義、帝國主義、種族主義之辨}

一直以來, 關於康拉德作品中殖民地人民及英國公民形象建構問題的討論追根溯源都會回到康拉德是 否是種族主義者、殖民主義者或帝國主義者的爭論上。這樣的爭論由來已久,最初是由尼日利亞著名作家欽 努阿・阿契貝 (Chinua Achebe)引發的,他於 1977 年發表了題為“非洲的一種形象: 康拉德《黑暗之心》中的 種族主義” “ “An Image of Africa: Racism in Conrad's Heart of Darkness”,1977) 的文章, 詳細解析了康拉德 
在其名作《黑暗之心》中對非洲人的“非人化” 描寫, 進而得出了康拉德是“一個血腥的種族主義者” 的結 論。之後, 著名學者沃茨 (Cedric Watts) 寫下 “ “一個血腥的種族主義者” : 關於阿契貝對康拉德的看法” “ “A Bloody Racist': About Achebe's View of Conrad”,1983)一文對阿契貝的觀點一一進行了駁斥。在兩人的帶 動之下, 後來又有不少學者陸續加人該論戰。大多學者的關注點都集中在康拉德是否是種族主義者這一論 點上, 但其實, 這其中還有另一個值得探討的問題。阿契貝在文章中只對康拉德作品中流露出的種族主義態 度進行了批判, 但沃茨卻在駁斥了阿契貝關於康拉德是種族主義者的指控後指出: “阿契貝明確表示, 只有 《黑暗之心》中所持的價值觀與他自己的相符, 包括對帝國主義的敵意, 他才能對其表示贊許”, 這也是一種 “意識形態上的帝國主義”, ${ }^{8}$ 似乎認為阿契貝揭露了康拉德的種族主義態度就是揭露了其帝國主義傾向, 將 種族主義和帝國主義劃上了等號。在另一篇關於《黑暗之心》的文章中, 沃茨也暴露出了同樣的問題。 事實 上, 除了沃茨之外, 參與該論戰的許多學者似乎都存在這一問題。還有的則是將帝國主義與殖民主義相等 同, 類似的學者國外的有霍金斯(Hunt Hawkins)、伊格爾頓( Terry Eagleton)、懷特( Andrea White) 等, ${ }^{\mathbb{1}}$ 國内 的包括侯維瑞先生、李賦寧先生等。 ${ }^{\mathbb{1}}$

概言之, 中外許多學者都對殖民主義、帝國主義與種族主義未加區分, 但其實三者雖然關係密切,卻差別 很大。種族主義關乎種族間的不平等地位, 並不必然導致殖民主義或帝國主義, 卻能為二者提供合理化依 據, 殖民主義和帝國主義又進一步使種族主義得到驗證。米爾斯 (Charles Mills) 和佩特曼 (Carole Pateman) 就認為殖民主義 “植根於 15 和 16 世紀在歐洲出現的種族和性別契約”。1 ${ }^{12}$ 詹森( Robert Johnson) 也認為“種 族主義總是伴隨著帝國主義”, ${ }^{1}$ 使其合法化。而關於殖民主義與帝國主義及兩者間的關係, 薩義德指出, “ “帝國主義”一詞指的是統治遙遠土地的宗主中心的實踐、理論和態度。幾乎永遠伴隨 ‘帝國主義”而來的 “殖民主義”, 意味著向邊遠土地上移民”。①在他看來, 殖民主義是比帝國主義更為具體的策略, 依附帝國主 義而產生。對此, 潘尼庫克 (Alastair Pennycook) 也表示贊同, 並強調“帝國主義相對於殖民主義而言是一個 更高級別的範疇, 殖民主義只是帝國主義的一個實踐場域”。總之, 大多學者都認同 “帝國主義可能涉及政 治統治、經濟掠奪及軍事征服, 也可能包括定居者或侵略者通過殖民擴大版圖的政策”, 更有著比殖民主義更 加廣泛的內涵, 而殖民主義只是帝國主義的一種手段。帝國主義當然也並不必然導致殖民主義, 只有 “當宗 主國的政策制定者認為直接的、有形的控制比間接的無形的控制更符合他們的利益時, 殖民主義才可能產 生”。田

而直接的、有形的控制往往涉及殘暴的殖民手段, 因此, 在大英帝國大肆進行殖民擴張的維多利亞時期,

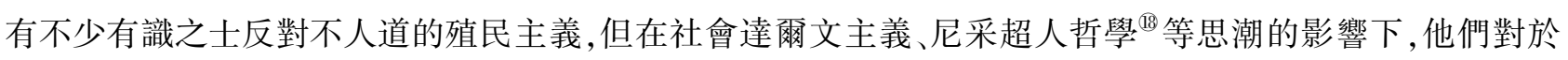
帝國主義和種族主義卻並無異議。處於這樣的時代背景之下, 康拉德自然也深受影響。他的作品正是一方 面對殖民擴張的不人道進行批判, 一方面又不時流露出帝國主義和種族主義態度。他雖然對傳統歷險小說 中的理想殖民紳士形象進行了顛覆, 但其作品中仍然不時有在殖民地權傾一方、廣受愛戴的英國紳士的身影 出現, 如《吉姆爺》(Lord Jim, 1900) 中的吉姆。雖然表現出對被殖民者的同情, 對他們中的部分人進行了頌 揚, 但這樣的頌揚只不過是居高臨下審視的結果, 他們終究不敵白人, 還是帶有野蠻人的影子。而且, 在康拉 德作品中, 只有部分殖民地人民獲得了話語權, 如《黑暗之心》中的黑人全都沒有話語權, 《進步的前哨》( An Outpost of Progress) 中的土著馬柯拉有話語權, 高比拉卻沒有。同時, 其作品中也不乏醜婳的他者形象, 如 《吉姆爺》中殘忍貪婪的阿郎酋長, 愚忠的唐 - 依塔姆和《海隅逐客》(An Outcast of the Islands) 中諂媚的阿 裏等。這一切都為康拉德反對殖民主義, 但卻支持種族主義和帝國主義提供了重要佐證。

如此, 也就不難解釋康拉德在剛果之行中雖見證了殖民者對非洲人民的暴行, 認為自己參與的事業“不 道德”, 卻仍在日記中以種族主義者的口吻描繪一個黑皮膚的白化病人, 說她長得非常具有黑人特點, 很醜 唡。回在途中給姑母寫信時, 他也還是把非洲人稱為 “黑皮膚的野蠻人”。 ${ }^{2}$ 因為在他心裏, 殖民擴張確實是反 
人性的, 但種族卻有高下之分。發現殖民真相只是讓康拉德對帝國殖民心存芥蒂,並未改變他對大英帝國的 認同。在 1914 年的採訪中,他就曾表示對於自己作為一個波蘭人,能用英語寫作,並且憑自己的努力成為一 名英國商船隊的船長感到非常自豪。①

在關於康拉德是否是種族主義者的著名論戰中, 阿契貝曾把康拉德稱為 “血腥的種族主義者”, 其實, 應該說康拉德確實是種族主義者, 但並不血腥, 其作品反對殘暴的殖民主義, 充滿著對殖民地人民的人道主 義同情, 只不過這樣的同情帶有濃烈的帝國主義色彩。或許是因為阿契貝自己也意識到了這一點,後來在將 該文作為其書的一部分出版時, 他把對康拉德的定位從“一個血腥的種族主義者” (“a bloody racist”) 改成了 “一個徹頭徹尾的種族主義者” ( “a thoroughgoing racist”) 。 ${ }^{3}$ 而關於康拉德對歷險小說傳統是繼承還是顛覆 的問題, 如果認清了其反對殖民主義但卻支持種族主義和帝國主義的本質，一切矛盾就會迎刃而解。康拉德 作品中繼承的, 是傳統歷險小說中的種族主義和帝國主義思想; 顛覆的, 是其中對殖民主義及殖民者形象的 美化,其實算得上是涇渭分明。

\section{二、對無私、能幹的傳統理想殖民紳士形象的顛覆}

基於上述立場, 康拉德在作品中對傳統英國民族身份進行了顛覆與改寫。但事實上, 原本康拉德心目中 的英國公民形象與傳統無異, 因為他從小聽著各類歷險故事長大, 受傳統歷險文學影響頗深。在這些故事 中, 英國人往往被塑造成高尚、文明的殖民紳士形象, 作為被上帝選中的子民,肩負著為殖民地人民帶來光明 和進步的使命, 毫無私心地幫助他們, 等到使命完成, 便又初心不改地回到英國。正是對如此美好的英國民 族身份的認知和㗽往, 康拉德到異域探險的渴望根深蒂固, 他 “從小就有一個秘而不宣的願望一一加人英國 海軍, 因為只有英國人才能成為一名真正的水手”, ${ }^{2}$ 才能實現他海上歷險的願望。於是, 他於 1878 年來到 倫敦, 想要實現他的夢想, 並於 1886 年加人了英國國籍, 同年 11 月還獲得了船長證書。1 890 年, 康拉德終 於如願踏上了剛果的土地, 但這次剛果之行卻使他親眼目睹了殖民活動的殘暴與血腥, 意識到了傳統理想英 國殖民紳士形象的虛假性和欺騙性。此後, 本來懷著㗽往和憧憬渴望參與殖民事業的康拉德變成了一個反 殖民主義者, 開始筆槍紙彈對殖民行為進行揭露和批判, 顛覆傳統的英國民族身份。

傳統歷險小說中的英國公民大多是以傳播文明為己任的殖民紳士形象,他們“往往把自己看作是強大 種族中的一員, 肩負著以自身形象重塑世界的使命”。康拉德作品中的英國公民到殖民地去卻大多是出於 個人原因, 通常是為了財富和利益, 全然沒有文明使者的神聖感, 如《卡倫:一段回憶》(Karain: A Memory) 中的英國人到東方去是為了做軍火生意, 《海隅逐客》中的林格船長則直接把森巴鎮變成了他賺錢的秘密基 地, 而《吉姆爺》中吉姆到帕圖森去更是因為在白人世界沒有容身之處, 是為了逃避自己不光彩的過去, 不得 已而為之。他們都是單純從自身利益出發考量之後, 才前往殖民地的, 與傳播文明的殖民紳士形象相去甚 遠。其實, 這是與康拉德本人的親身經歷相呼應的, 在其剛果之行中, 大家都是為了象牙而去的非洲, 貿易站 經理是一個象牙商, 他們所有的工作都圍繞象牙展開, 與傳播文明無涉。 因此, 在康拉德的自傳體小說《黑 暗之心》中, 當馬洛的姨媽對其大談她為馬洛介紹的公司以解救當地人為己任時, 馬洛 “冒昧地暗示, 該公司 的目標, 是賺錢”。②

此外, 白人殖民者在殖民地的處境也並沒有傳統歷險小說中描寫的那樣誘人, 其中對他們來說最大的困 擾便是各種熱帶疾病的侵襲。相應地, 英國殖民者也並非傳統歷險文學中描寫的那樣無所不能。19世紀末 20 世紀初, 雖然防治熱帶疾病的技術已經有了很大進步, 奎寧的使用也大大降低了歐洲人在殖民地的死亡 率, 但疾病仍然是殖民進程中的最大障礙之一。如在 1874 年英軍人侵阿散蒂王國的過程中, 雖然有奎寧, 兩 個月内英軍患病的死亡率還是達到了每千人 17 個的比例。正如學者亞桑諾夫 (Maya Jassnoff) 所指出的, 
Asia-Pacific Journal of Humanities and Social Sciences

“身處於赤道非洲的歐洲人其實是很脆弱的, 他們是一個完全依賴當地人供應食物的小型群體, 而且還非常 容易得病, 是技術優勢的運用才讓他們得以取得成功”。局時,據康拉德瞭解, 由於發燒和痢疾,其所在公司 到非洲去的人中有 $60 \%$ 都沒能在那工作滿半年, 剩下的很多人也在快滿一年的時候被匀忙送回國, 以防死 在剛果。最終按照合同幹滿 3 年的人只占 $7 \%$, 還都是法國人, ${ }^{9}$ 這些都與傳統歷險小說中英國人從殖民地 功成身退的描寫形成了巨大反差。康拉德在日記中也有記錄許多同伴發燒嘔吐乃至不能行走的情形, 他自 己其間也深受發燒和痢疾困擾。因此,傳統歷險小說中的英國公民大都是“能幹、獨立,可以馴服及控制環 境的”殖民紳士形象, ${ }^{30}$ 但康拉德筆下的英國殖民者卻並沒有那麼能幹, 且都受制於環境, 如《黑暗之心》中的 英國敘事者馬洛就是帶著發燒的症候返回英國的。

而《海隅逐客》中的林格船長看似是傳統的歷險英雄, 誠實、能幹, 又勇敢,但作為船長, 他竟然因為操作 失誤丟了自己的船, 最後還在去歐洲淘金時失蹤了,同樣與無所不能的傳統英國紳士形象存在差距。而且他 自認為自己幫助當地人解決爭端, 維持秩序, 給他們帶來了繁榮和幸福, 他們一定會感激他。但事實並非如 此, 土著巴巴拉虫說出了真相: “你們白人已經拿走了一切: 土地、海洋, 以及打人的權力。在這些島上, 除了 你們白人的正義之外,什麼都沒給我們留下”。影所以其實他一直活在自以為是的幻境中, 對自己和當地人都 抱有錯誤認識。說到底,他只是一個自欺欺人的殖民者。在康拉德生活的年代,帝國主義甚㽞塵上,英國民 眾大多受到殖民宣傳影響, 對殖民事業及殖民者形象抱有錯誤認識, 自詡高貴。一旦親身參與殖民活動, 理 想就會觸礁, 林格船長和康拉德本人都是其中的代表, 類似的形象還有很多, 如《黑暗之心》中的庫爾茲和 《吉姆爺》中的吉姆。庫爾茲原本打算到殖民地大顯身手, 卻變得腐化墮落、利忿薰心, 最終充滿恐懼地病死 在非洲的土地上, 臨死前嘴裏還不停地念叨著: “可怕呵! 可怕啊!”, 雨暴露出了殖民者真實而又脆弱的一 面。吉姆本來對殖民歷險充滿憧憬和鄉往, 以為自己“永遠都會是忠於職守的榜樣,並且像書中的英雄一樣 毫不退縮”。但面臨危機,卻“嚇得喘不過氣來”, ${ }^{3}$ 後來在生死敒關的風暴面前,選擇了棄船逃生。這些形 象都是受到殖民宣傳㽬惑, 無法正確認識自己的典型代表。康拉德通過書寫揭露並諷刺了英國殖民者對自 身的錯誤定位，以及殖民主義的欺騙性。從中,我們看到的是不堪一擊的弱者形象。

不同於傳統歷險小說,康拉德作品中不乏到殖民地謀取利益、脆弱無能的英國公民形象,這樣的形象無 疑更加真實, 是他以親身經歷為依據, 重新思考英國民族身份問題的必然結果, 也是其改寫英國公民形象的 基石。

\section{三、對勇於承擔、具有人道主義精神的帝國紳士形象的建構}

由於康拉德反對殘暴的殖民政策, 意識到了大英帝國在殖民擴張中犯下的罪行, 其在作品中塑造了不少 犯錯的主人公, 而且他們大都在犯錯之後重新開始, 似乎透露出康拉德對大英帝國在殖民擴張方面改弦更張 的殷切希望,因為他畢竟對大英帝國仍然是懷有期待的。康拉德出生於沙俄統治下的波蘭,因其父參與並領 導波蘭愛國運動,童年時的康拉德便與父母一起被流放到了西伯利亞。其母不堪如此變故,加之環境艱苦, 患病於康拉德 8 歲時病逝,其父也在他 11 歲時去世,成為孤兒的康拉德被舅父收養,所以因祖國被侵略而流 離失所、家破人亡的康拉德從小就深知祖國強大的重要性,十分渴望獲得強大祖國的庇護,渴望成為“自由 國家的自由公民”。因此後來踏上英國的土地, 目睹了英國的強大、富足、民主與獨立, 便於 1886 年加人了 英國國籍。雖然在剛果之行中發現了殖民擴張的真相,但康拉德只是對殖民這樣一種帝國建構方式頗有微 詞, 認同的仍然是強大民族英國的民族身份。而對於落後的弱小民族, 康拉德頂多是居高臨下地憐憫與同 情,並未真正認同,所以作品中才會出現諸多種族主義暗流。

基於這樣的出發點,康拉德筆下的英國公民雖然還是英國紳士, 卻反映出了他對紳士內涵的獨特理解。 
在康拉德生活的維多利亞時代, 英國紳士大多 “出身中上社會階層, 道德意識強, 性格堅韌, 具有社會責任感 和男子氣概”。 ${ }^{30}$ 康拉德作品中的英國紳士並非如此, 但卻有一個過人之處, 那就是在鑄成大錯之後能及時醒 悟, 甘願受罰, 成為勇於承擔的帝國紳士。如《吉姆爺》中出身牧師家庭的吉姆作為船員, 面臨危險時棄船逃 生, 置八百多名乘客於不顧, 實在有違紳士風範, 但在犯錯後他及時悔過, 不推諉, 不逃避, 勇於承擔後果。 “他很清楚就算他跑掉, 也不會有人費心去追他的”, 卻仍勇敢地獨自出庭受審, 面對千夫所指。吉姆是做 錯了, 但他並沒有逃避罪責, 而是坦然面對, 勇敢承擔。如果說臨陣脫逃違背了紳士品格, 敢作敢當卻又值得 敬佩。吉姆棄船事件是康拉德以真實事件為基礎進行的再創作, 真實事件中 “聖吉達號” ( S. S. Jeddah)上 的船員大多為英國人, 棄船逃生之後英國船長一行人出庭並受到了嚴厲審判。但小說中 “帕特納號” 的船長 卻變成了德國人,他在棄船逃生之後為躲避審判再次逃跑, 其他未指明具體國籍的歐洲船員則稱病躲在醫 院, 英國大副吉姆成了庭審中 “唯一能夠並且願意到場的那個”。 ${ }^{8}$ 通過改編, 康拉德突出了吉姆異於他國船 員的承擔精神及責任感。

而在誠心悔過和接受懲罰之後, 吉姆也在東方世界帕圖森獲得了新生, 成了“受人愛戴、受人信賴、受人 欽佩” 的吉姆爺。 ${ }^{39}$ 但在輕信白人海盜布朗, 導致當地土著頭人之子死亡後, 他再一次勇敢地面對自己的錯 誤, 明知會有生命危險, 仍然登門請罪, 形同自殺。人生中兩次犯錯, 他都能做到知錯改錯, 為自己的行為負 責, 並且為了維護這樣的紳士形象不惜拿前途和生命去交換, 如此勇於承擔的紳士形象正是康拉德心目中真 正的英國紳士。真實事件中的大副威廉姆斯自然沒有像吉姆一樣在帕圖森功成名就的傳奇經歷, 只是在該 事件的困擾下過完了平凡的一生, 康拉德對吉姆兩次承擔錯誤的刻畫反映出了他對大英帝國及英國殖民者 改過自新的期待。

既然在康拉德心目中,不應該以暴力血腥的方式建構帝國,那麼,在他看來什麼樣的帝國才是最理想的 呢? 這樣的帝國又需要什麼樣的帝國衛士? 要探究康拉德本人對帝國的態度和看法, 還是需要回溯其人生 經歷。康拉德對故國波蘭有著深厚的感情, 並且對波蘭的自由、民主等優良品質十分贊許。康拉德指出, 波 蘭雖然也有內戰, 但其內戰都“遵循人道主義原則, 戰後沒有遺留下任何敵意和壓迫感, 當然也沒有留下仇 恨”, 四對波蘭所具有的人道主義精神作了反復強調, 他心目中理想的帝國正是像波蘭一樣擁有這種精神的 帝國。而對於如何使帝國發展壯大, 也可以在康拉德的自述中找到答案。康拉德指出, 波蘭從未侵略過他 國,並不熱衷於領土擴張, 雖曾合併立陶宛和魯塞尼亞, 但並未訴諸武力, 而是出於經濟、社會和道義方面的 考量。同時, 康拉德還進一步以讚頌的口吻談到 “該聯盟內部各國人民的意見總是能始終如一地達成一 致”, 說明康拉德推崇的是通過協商, 為了共同利益聯結在一起的帝國聯盟。帝國內部也總是能自主自願 地達成一致意見, 相互忠誠,所做的決定都是出於聯盟內部的共識。

在康拉德作品中, 這樣的帝國以及奉行這一理念的帝國建構者確實也都有跡可循。如在《吉姆爺》中, 吉姆前往東方世界帕圖森之後, 為當地人鞠躬盡瘁, 憑藉非凡的才幹、膽識、誠實與正直, 以及白人老爺的身 份建立起了自己的威望,他並未進行殖民,也沒有承擔任何行政職務, 卻是當地 “實質上的統治者”, 車大家都 無比信任他, 把他說的話奉為金科玉律, 甚至連生活瑣事也會找他決斷, 對他又敬又愛。從某種程度上來說, 帕圖森就是吉姆的帝國, 只是這樣的帝國是基於人道主義精神的建構, 是他與當地人兩廂情願, 共同建構起 來的。這正是康拉德理想中的帝國狀態, 沒有不必要的殺翏和暴力, 其他民族因為真心敬服歸而化之。《海 隅逐客》中林格船長的帝國建構實踐卻是一個反面例證, 林格船長也試圖在森巴鎮建立自己的統治, 他在當 地通過壟斷貿易樹立起了自己的權威, 比族長巴塔魯魯更有實權, 但由於缺乏像吉姆一樣的公信力, 最終其 他商家的介人瓦解了他的統治, 說明在康拉德看來, 當時盛行的劃分殖民地以㩖取壟斷利潤的做法並非長久 之計, 只有以自身實力為基礎, 吸引其他民族真心歸附, 才能持久, 其所推崇的正是通過人道主義精神建構帝 國的帝國紳士。林格船長這一形象也是根據真實人物改編而成的, 康拉德基本採用了威廉 - 林格 (William 
Lingard) 的真實事例, 卻在吉姆的東方傳奇中做了文章, 除為了迎合當時的讀者趣味之外,也是其自身政治 立場的映射。

同時,由於康拉德的種族主義傾向,在他心目中英國血統是容不得他國人來玷污的,因此其作品中英國 公民與他國人或混血兒的感情全都無疾而終, 以悲劇收場,如英法混血兒庫爾茲與其英國未婚妻,英國紳士 吉姆與混血女子珠寶最終都陰陽兩隔。但事實上, 吉姆及林格船長的原型在現實中都與東方人婚配並終老, 小說中除吉姆與珠寶結局淒慘之外,林格船長並未娶妻,康拉德做此改編用意不言而喻。此外,康拉德作品 中的混血兒往往處境尷尬,或是產生認同障礙,如荷蘭人奧邁耶的女兒妮娜不知道自己該跟父親一樣認同西 方文化還是像母親一樣認同東方文化, 或是直接被歸人東方人行列, 如邋遢的喬安娜, 或是只能做東方人的 工作,如替庫爾茲押送象牙的混血職員。康拉德的這些書寫反映出了他對純正血統的偏好,而這也與時代語 境相契合。彼時種族之間的界限十分明晰, 難以逾越, 混血兒卻 “質疑了這種界限的持久性”, 皮威脅到了歐 洲人的特權, 是需要被禁絕的。

綜上可知,康拉德筆下的英國公民雖然還是英國紳士,但卻具有不同的特質。他們是像平常人一樣有缺 點、會犯錯,但卻能知錯就改,勇於承擔,擁有人道主義精神和純正英國血統的帝國紳士。

\section{結語}

傳統歷險小說中塑造的英國公民往往都是高尚、文明、正直、勇敢的理想殖民紳士形象。康拉德在剛果 之行以後深刻意識到了此類殖民話語及殖民英雄形象的虛假性和欺騙性, 對傳統的英國公民形象進行了顛 覆和改寫。然而, 由於康拉德反對暴力血腥的殖民行為, 但卻支持大英帝國的建構, 認同西方中心論, 是一個 反對殖民主義的帝國主義者和種族主義者, 他在對歷險小說傳統進行顛覆的過程中, 顛覆的是與殖民主義相 關的元素,卻保留了契合帝國主義及種族主義語境的內容。因此,其筆下的英國公民不再是理想的殖民紳士 形象,而是基於傳統,但卻也彰顯著他自己對英國紳士內涵獨特理解的擁有純正英國血統,勇於承擔, 又具有 人道主義精神的帝國紳士形象。在目睹殖民暴行之後, 康拉德對殖民擴張及殖民者的醜陃進行了揭露和批 判,但其深人骨髓的帝國主義及種族主義思想使得他內心深處真正認同的還是大英帝國,對於落後的弱小民 族則只有居高臨下的俯視及同情。當然, 無論康拉德是否是殖民主義者、帝國主義者或種族主義者,都無法 抹㛀他作為一名文學巨匠的成就,但這種解讀方式為研究康拉德作品中的英國民族身份建構問題帶來了一 種新的視角,也為理解康拉德本人及其作品提供了一種新的思路。

\section{注釋}

(1) 殷企平: 《《黑暗的心臟〉解讀中的四個誤區》,《外國文學評諭》2001 年第 2 期, 頁 144-151。

(2) (4) (8) Watts, C. (1983). “A bloody racist”: about Achebe's view of Conrad. The Yearbook of English Studies, (Colonial and Imperial Themes Special Number), 196-209.

(3) YUAN Jingjing. (2021). Human, cyborg, and subjectivity in Good Hunting: a posthuman deconstructive perspective. Asia -Pacific Journal of Humanities and Social Sciences, 1(1), 32-38.

(5) [以]愛德華・薩義德著, 王宇根譯:《東方學》, 三聯書店 1999 年版, 頁 426。

(6) 歸化作家, 即“出生在英國殖民地, 或出生在其他帝國主義國家, 後來來到英國本土接受教育、生活或工作, 最後加入了 英國籍的非盘格鲁一薩克遜民族後裔的作家”。詳見趙海平著:《約瑟夫・康拉德研究》, 大眾文藝出版社 2007 年版, 頁 66 。

(7) (22) Achebe, C. (1977). An image of Africa: racism in Conrad's Heart of darkness. The Massachusetts Review, 18(4), 782 -794 .

(9) 詳見 Watts, C. (1996). "Heart of Darkness”. In J. H. Stape (Eds.), The Cambridge companion to Joseph Conrad. Cam- 
bridge: Cambridge University Press, 45-62.

(10) 詳見 Hawkins, H. (1979). Conrad's critique of imperialism in Heart of darkness. Modern Language Association, 94(2), 286-299 中的第 297-298 頁;Eagleton, T. (1978). Criticism and ideology: a study in Marxist literary theory. London: Verso 中 的第 135 頁; White, A. (1996). Conrad and imperialism. In J. H. Stape (Eds.), The Cambridge companion to Joseph Conrad. Cambridge: Cambridge University Press 中的第 181 頁。

(11) 詳見侯維瑞著:《現代英國小說史》, 上海外語教育出版社 1985 年版中的第 137 頁。李賦寧著: 《歐洲文學史(第三 卷) 》, 商務印書館 2001 年版中的第 33 頁。

(12) Darity, W. (2008). International encyclopedia of the social sciences (Volume 2). London: The Gale Group, 12.

(13)16) Johnson, R. (2003). British imperialism. New York: Palgrave Macmillan.

(14) [以]愛德華・薩義德著, 李琨譯:《文化與帝國主義》, 三聯書店 2003 年版, 頁 9 。

(15) Pennycook, A. (2002). English and the discourses of colonialism. Taylor \& Francis e-Library, 35.

(17) 轉引自高岱、鄭家馨著:《殖民主義史 (總論卷)》, 北京大學出版社 2003 年版, 頁 149 。

(18) 尼采宣稱上帝已死, 需要對一切價值進行重新評估。他呼鰂超人的出現以拯救人類的墮落, 提倡超越自己、超越弱者, 向超人統治的世界進化。

(19) Conrad, J. (1926). Last essays. Garden City \& New York: Doubleday, Page \& Company, 165.

(20)(29) Conrad, J. (2015). The selected letters of Joseph Conrad (Volume 6). Cambridge: Cambridge University Press.

(21) Jezierski, B. A., Conrad, J. \& Drabowski, M. (1944). An interview with Joseph Conrad. The American Scholar, 13 (3), 371-375.

(23) Achebe, C. (1990). Hopes and impediments: selected essays. New York: Anchor Books.

(25) Kumar, K. (2003). The making of English national identity. Cambridge: Cambridge University Press.

(26) 詳見 Conrad, J. (1926). Last essays. Garden City \& New York: Doubleday, Page \& Company.

(27) (32) Conrad, J. (1995). Joseph Conrad: three novels. London: The Macmillan Press.

(28) [美] 馬㛏 - 亞桑諾夫著, 金國譯:《守候黎明: 全球化世界中的約瑟夫 ·康拉德》, 會科學文獻出版社 2018 年版, 頁 244 。

(30) White, A. (1993). Joseph Conrad and the adventure tradition. Cambridge: Cambridge University Press, 159.

(31) Conrad, J. (1928). An outcast of the islands. New York: Doubleday, 229.

(33)(34)(38(39) Conrad, J. (1993). Lord Jim. Hertfordshire: Wordsworth Editions Limited, 5-171.

(35) Conrad, J. (1964). Conrad's polish background: letters to and from polish friends. London: Oxford University Press.

(36) 陳兵:《責任與疆界:毛姆東方故事中的英國紳士與帝國》,《外國文學》2016年第 4 期, 頁 109-17。

(40) TANG Ping. (2021). "Let me unseal the letter": letters as narrative in Shakespeare's King Lear. Asia-Pacific Journal of Humanities and Social Sciences, 1(3), 166-173.

(41) Conrad, J. (1928). Notes on life and letters. Garden City \& New York: Doubleday, Doran \& Company, Inc, 120-132.

(43) Füredi, F. (2004). Crossing the boundary: the marginal man. In J. O. Ifekwunigwe (Eds.), “Mixed race” studies: a reader. Taylor \& Francis e-Library, 69-72.

(Editor: Jasmine Liu) 